\title{
LOS ADVERBIOS DE FOCO A TRAVÉS DE LA TRADUCCIÓN: COMPARACIÓN DEL CHECO Y DEL ESPAÑOL
}

\author{
Miroslava AurovÁ \\ Universidad de Bohemia del Sur, České Budějovice
}

\begin{abstract}
En): Translated texts and parallel corpus offer a source of relevant data and have their place already established in Contrastive Linguistics and in Translation. However, it is legitimate to postulate questions about the limits of the research based on the parallel corpus and on the possible factors that could influence when drawing conclusions about the linguistic system based on the data obtained from such corpus. The objective of this article is, therefore, to reflect on these aspects through a study of particles, specifically of the focus adverbs (rhematizers). These are observed in translated texts from Czech to Spanish (and vice versa) and analyses of translations by each translator are included to answer the question whether this type of analysis reveals the systemic linguistic facts or individual factors determined by the translator.
\end{abstract}

Keywords (En): focus adverbs; particles; parallel corpus; translation

Palabras clave (Es): adverbios de foco; partículas; corpus paralelo; traducción

\section{Introducción}

Los textos traducidos del español al checo y viceversa y sus análisis detallados son una valiosa fuente de datos de interés e importancia para la lingüística tanto a nivel de la indagación teórica, como a nivel de consecuencias sumamente prácticas - la traductología. En esta contribución, por tanto, nos gustaría presentar un análisis parcial, realizado a través de textos traducidos, de uno de los fenómenos estrechamente relacionados con la Perspectiva Funcional de la Oración (en adelante, PFO): concretamente, las partículas que sirven para señalar el foco -los adverbios de foco. Sin embargo, la presentación de los resultados no es el único objetivo del artículo; todo lo contrario, nos centramos también en otros aspectos. Especialmente, dado que hemos trabajado con textos traducidos, nos ha interesado, lógicamente, plantear la pregunta de hasta qué punto los datos obtenidos a través del corpus de textos traducidos revelan $-\mathrm{o}$, mejor dicho, pueden revelar- las manifestaciones del sistema lingüístico.

Para conseguir nuestro objetivo, estructuraremos el texto de la siguiente manera: concluida la introducción, se presentarán los aspectos generales de la PFO desde la perspectiva contrastiva (entre el checo y el español) para proceder, a continuación, a la exposición del tema de los adverbios de foco en cuanto a que se relacionan con la PFO en general, para centrarnos después en dos casos concretos: en los focalizadores checos alespon̆ («al menos») e $i$ («y», «incluso»). Finalmente, apoyándonos en otro análisis, intentaremos exponer algunas ideas relacionadas con los límites del análisis de textos traducidos en general. 


\section{La PFO en la traducción: el contexto como factor decisivo}

En las publicaciones anteriores (AUROVÁ, 2016 y 2017) hemos sostenido que en el checo, lengua flexiva, se imponen fuertemente los principios de la PFO, hecho reflejado especialmente en el ordenamiento de los elementos oracionales, mientras que el español, a causa de restricciones de naturaleza sintáctica, no permite que se imponga la PFO de la misma medida que en la lengua checa. En este punto, nos referimos al hecho de que el checo, por lo general, dispone de una libertad de orden de palabras sintáctico mayor que la que se observa en español. Consecuentemente, esta «libertad» del checo conduce a la producción de ordenamientos mucho más variados, incluso de los que el sistema lingüístico español rechazaría como agramaticales, como se ve en el siguiente ejemplo, pronunciado con entonación no marcada, neutral:

(1) a. Tu televizi vám Jirka spraví do dvou dnů.

b. *La tele os Jorge arreglará en dos días.

Puede constatarse que cada lengua, gracias a su sistema gramatical interno, tiene su propio grado de sensibilidad ante la «novedad» (o giveness) de la información proporcionada, por lo cual la estabilización del orden de palabras alcanza niveles distintos en las lenguas. Este hecho se refleja claramente en la necesidad de reordenar los elementos en los textos traducidos: así, si conservamos el orden de palabras del texto origen, pueden producirse, en algunos casos, malentendidos o incluso secuencias agramaticales en el texto meta. Puede decirse, grosso modo, que, al traducir del checo al español, deben considerarse las exigencias del sistema sintáctico, pero la traducción del español al checo debe ajustarse estrictamente a la PFO, en especial, debería tenerse en cuenta la información conectada al contexto previo y reordenar, en contextos de orden no marcado, la información en dirección desde lo «conocido» hacia lo «nuevo». El contexto, pues, se impone como factor decisivo, en el que actúan, en palabras de LEVÝ (1967), las instrucciones selectivas. Por lo tanto, en la traducción del español al checo, debido a su orden sintácticamente libre, aumenta considerablemente el paradigma de posibilidades sistémicas con el que trabaja el traductor en su proceso decisorio, a las que se aplican, según LEVÝ (1967), las instrucciones selectivas tanto las obligatorias, como las facultativas.

Para ilustrar brevemente ambos tipos de instrucciones en el ámbito del orden de palabras, acudiremos a un par de ejemplos (para más detalles, véase AUROVÁ, 2016a). El párrafo en (2), tomado de ATIENZA PEÑARROCHA (2007), establece un contexto cuya continuación directa son las oraciones en (3) y (4). Fijémonos en la expresión Felipe II que se menciona en (2) y se repite en (4), donde representa una información no completamente nueva, sino, al contrario, una información previamente mencionada, «conectada al contexto», «conocida». Debido a este contexto, según los requisitos del sistema de la PFO en checo, se convierte esta expresión en un elemento de menor grado de dinamismo comunicativo, lo cual repercutirá en su posición dentro del enunciado. Observemos las posibles traducciones de la última oración (4) al checo, presentadas en (5). 
(2) A la muerte del rey don Sebastián de Portugal en Alcazarquivir, en 1578, Felipe II reclamó el trono de Portugal como herencia de su madre, Isabel. Una rápida campaña, dirigida por el duque de Alba por tierra y por Álvaro de Bazán, marqués de Santa Cruz, por mar, terminaron con la escasa oposición y Felipe II se convirtió en rey efectivo. Pero parte de los portugueses, recelosos ante el rey de España, apoyaron al pretendiente, Antonio, Prior de Crato, hijo natural del duque de Beja.

(3) Antonio solicitó apoyo en Londres y París, obteniendo promesas y dinero.

(4) Londres le prestó cierto apoyo para complicar la existencia de Felipe II [...]

(5) a. ??Londýn mu určitou podporu poskytl, aby zkomplikoval život Filipovi II b. Londýn mu určitou podporu poskytl, aby Filipovi II. zkomplikoval život. c. Londýn mu určitou podporu poskytl, aby zkomplikoval Filipovi II. život.

La primera traducción en (5a) mantiene el orden de palabras de la lengua de origen, en el que la expresión Felipe II - Filipovi II (en dativo) ocupa la posición final. No obstante, dado que la posición final en un enunciado con entonación no marcada está reservada para los elementos de mayor grado del dinamismo comunicativo (end-focus principle), violaría esta traducción los principios de la PFO. Esto no ocurre en las traducciones (5b) y (5c), donde el elemento Filipovi II. está fuera de la posición asignada al foco propio (foco estrecho). Para resolver este impedimento, se ha tenido que desplazar el elemento Filipovi de la posición final a una pre-final. Consideramos este tipo de ajuste del orden de palabras como obligatorio, a diferencia de lo que se observa en los ejemplos en (5b) y (5c), donde ninguna de las posibilidades del paradigma viola el principio de la $\mathrm{PFO}$, quedando así la decisión al juicio final del traductor. La elección entre la variante (5b) o (5c) representaría, de este modo, la instrucción selectiva facultativa en términos de LEVÝ (1967).

Una situación similar se observa en la traducción del siguiente ejemplo. A diferencia del caso anterior, donde el contexto desempeñó un papel principal para la selección/decisión, la frase en (6a) encabeza el capítulo y deja así abierta la interpretación de la estructura informativa. La traducción, desde el punto de vista del orden de palabras, puede ser doble, como se observa en (6b) y (6c). Ambas versiones son perfectamente aceptables: cada una enfoca una realidad transmitida desde un punto de vista diferente: mientras que la secuencia (6b) corresponde a la escala presentativa, el orden de la secuencia en (6c) indica la escala calificativa (para más detalles, véase AUROVÁ, 2017). ${ }^{1}$ Es obvio que, otra vez, estamos ante una instrucción selectiva facultativa.

(6) a. En marzo volvieron los gitanos.

b. V březnu se cikáni vrátili.

en marzo REFL gitanos volvieron

c. V březnu se vrátili cikáni.

Con este breve resumen hemos pretendido evidenciar nuestro punto de partida para la argumentación consecuente, en particular, la idea de que, en el proceso traductológico, también en los niveles superiores a los morfosintácticos y

\footnotetext{
${ }^{1}$ Aquí nos referimos a las escalas del dinamismo comunicativo, concepto propuesto por Firbas (1974), (1989) y elaborado por Adam (2011), (2014), entre otros.
} 
semántico-léxicos, se aplican las instrucciones selectivas, siendo el contexto el agente decisivo de mayor peso. En el ámbito de los llamados focalizadores, adverbios de foco, esperamos una situación similar: el contexto se establecerá como factor crucial para interpretar la semántica de los focalizadores y para incorporarla en textos meta durante el proceso de trasvase. ${ }^{2}$ Partimos de la idea de que si el traductor se encuentra con una señal de operación semántica-procedural (el focalizador) en el texto de origen, reaccionará de alguna manera para reflejarla en el texto meta. Para cotejar las tendencias que pueden producirse al respecto, hemos acudido a una serie de análisis, cuyos resultados (parciales) se presentan a continuación.

\section{Los adverbios de foco}

\subsection{Equivalencias sistémicas entre el checo y el español}

Si la función de la PFO es dejar evidente cómo el emisor presenta (o quiere presentar) la información según la escala desde lo (con)sabido hacia lo nuevo o no implicado en el contexto (co-texto) previo, el orden de palabras no es el único recurso de la señalización de las partes temáticas y remáticas. Tanto el español como el checo disponen de otros medios, como son la prosodia (entonación neutra/focal), construcciones sintácticas (las relativas de foco: fue Juan el que lo dijo) y toda una serie de elementos léxicos. La diferencia entre ambas lenguas reside en la cuestión del repertorio, de la sistematicidad, frecuencia y productividad de estos recursos.

Lo que nos interesa ahora son especialmente las diferencias del uso de los elementos léxicos, comúnmente llamados como adverbios de foco; estos reciben en la lingüística checa reciente la denominación actualizadores. Los focalizadores actualizadores, como deriva de su nombre- «actualizan» el foco, es decir, acompañan y subrayan la información remática (el rema o el rema propio) de modo que la mera aparición del «actualizador» (focalizador) $)^{3}$ ayuda a identificar, de manera unívoca, al rema, incluso en casos en los que el rema no ocupa su posición canónica final (es decir, en casos en los que no se observa el llamado end-focus principle). Tal mecanismo, compartido por ambas lenguas, aporta a la indudable interpretación de lo que se presenta como información conocida y de lo que se presenta como información nueva. ${ }^{4}$ Subrayemos que el mecanismo está condicionado por el contexto, a cuya interpretación, a su vez, contribuye el adverbio

\footnotetext{
${ }^{2}$ Con el término trasvase nos referimos a la dicotomía terminológica y conceptual propuesta por Jiří LEVÝ en el campo de la traductología: el trasvase como proceso y la traducción como resultado. Términos según la traducción por KRÁlovÁ, CUENCA DrouHART (2013).

${ }^{3}$ El término «actualizador» tiene su tradición en la lingüística checa, ya que remite a la idea que surgió ya en los primeros momentos del Círculo Lingüístico de Praga: el orden de palabras «actualizado» del enunciado, frente al orden de elementos sistémico (profundo) de la oración. Este mecanismo se reflejó en la denominación original división actuelle de la phrase, convertida después al inglés como functional sentence perspective.

${ }^{4}$ Hay que advertir que la información remática (focal) no es la única que puede estar reforzada por los focalizadores; son también el tema contrastivo y el tema base los que aparecen acompañados de tales elementos. En el siguiente ejemplo, el focalizador incluso acompaña la parte temática, mientras que el adverbio solo se relaciona con el foco propio:
}

(i) Incluso Tomás conoce de las obras de Goethe solo la novela. 
de foco, sobre todo gracias a su función de operador, cuyo papel reside, generalmente, en desencadenar algún tipo de implicatura. De esta manera, el adverbio de foco incluso en el ejemplo (7), además de implicar la existencia de un conjunto de entidades, indica la inclusión de un elemento a dicho conjunto, pero también sitúa al elemento señalado en uno de los extremos de la escala presupuesta/implicada. Es obvio que el focalizador incluso se refiere al límite de la escala propuesta, es decir, al miembro último del conjunto presupuesto. Por su parte, el adverbio solo en (8) predica que no existe ningún individuo dentro del conjunto que sepa algo, excepto Andrés (RAE-ASALE, 2009 : §40.9a):

(7) a. En su inactividad, don Bernardo dejó incluso de visitar a mediodía, con sus amigos, la taberna de Dámaso Garabito.

b. Ve své nečinnosti zanechal don Bernardo dokonce poledních návštěv hospůdky Dámase Garabita se svými přáteli. ${ }^{5}$

(8) a. Solo Andrés lo sabía.

b. Pouze Andrés to věděl. ${ }^{6}$

Si comparamos esta característica básica de los focalizadores en ambas lenguas más detalladamente, vemos que estos elementos coinciden, tal y como suele explicarse en la literatura al respecto, ${ }^{7}$ en establecer su ámbito operativo en el que forman con la expresión a su alcance un conjunto que, dentro del enunciado, puede tener cierta variabilidad posicional. De esta manera, la información remática puede estar fuera de su posición típicamente final, hecho que no impide la correcta interpretación del rema gracias a la presencia del actualizador (aparte del contexto, obviamente).

Además, en ambas lenguas encontramos focalizadores con rasgos semánticopragmáticos similares: los que generan presuposiciones sobre inclusión-adición (también/taky), sobre exclusión-restricción (solo/pouze), sobre escalaridad (hastal dokonce, al menos/alespoň), sobre intervalo temporal (ya/už), etc.

De lo expuesto hasta ahora deriva claramente que, desde el punto del sistema lingüístico, la similitud entre ambas lenguas llega a niveles altos, sin embargo, como veremos en los siguientes apartados, una mirada minuciosa revela asimetrías significantes, que pueden atribuirse al sistema lingüístico per se, y que resumimos en los siguientes dos apartados, para examinar después el factor de la traducción en el capítulo 2.

\subsection{El adverbio de foco alespoň: ¿caso de simetría?}

La expresión alespoň («al menos», «por lo menos») pertenece a los actualizadores restrictivos, comprendidos por la tradición lingüística checa como elementos que restringen la validez de cierta afirmación solo a la expresión afectada

\footnotetext{
${ }^{5}$ Traducción propia del ejemplo tomado de RAE-ASALE (2009: $\left.\$ 40.8 b\right)$.

${ }^{6}$ Traducción propia del ejemplo tomado de RAE-ASALE (2009: §40.9a).

${ }^{7}$ Como obras de referencia nos han servido Uhlířová (1987), DANeš, GrePl, Hlavsa (1987); HAJIČOVÁ (1995) y SGALl, HaJIČOvÁ (1997), ŠTĚPÁNKOVÁ (2014) de la lingüística checa; por parte de la española, Kovacci 2000, FerRari et al. (2011), SÁnchez LóPEz (1999), LAGUnilla, DE Miguel (1999), RAE-ASALE (2009).
} 
por el adverbio de foco, como ocurre con la palabra šáleček («tacita») en el ejemplo (9a). En la traducción (9a') al español, el sema de restricción del conjunto a la entidad mínima está conservado: está expresado también por un rematizador, el adverbio al menos con el mismo significado, entendido por la lingüística española como adverbio de foco de exclusión (ya que excluye a todos los miembros del conjunto inferido, exceptuando a la expresión afectada por el actualizador). El lexema alespon̆ (aspoň) puede traducirse al español también como al menos (9a), por lo menos (9b) o tan solo (9c). Su sema de restricción/exclusión queda patente también en las construcciones sintácticas concesivas (9d).

(9) a. Alespoň jeden šáleček, prosím vás.

a'. - Al menos una tacita, se lo ruego.

b. Opět mne bere $\mathrm{k}$ tanci, šlápla jsem mu na botu a on řekl, zdali z lásky alespoň té bývalé.

b'. Me llevó de nuevo al baile, le pisé un pie y él dijo: «Por amor, por lo menos por el amor pasado».

c. Vzhledem k tomu, že k podrobné analýze zde není časový prostor, dovolte alespoň několik poznámek.

$\mathrm{c}^{\prime}$. Puesto que no hay tiempo para un análisis detallado, permítanme hacer tan solo unos cuantos comentarios.

d. Ale príteli, nebud' tak lakomý, dej mi alespon̆ malý kousek!

$\mathrm{d}^{\prime}$. -Pero, amigo, no seas tan egoísta, dame aunque sea un poquito .

De todo esto puede deducirse que ambas lenguas disponen de un elemento léxico de alto grado de equivalencia que se observa en los siguientes rasgos: tanto alespon̆ como sus equivalentes españoles (i) se relacionan con el foco, (ii) establecen presuposición sobre la existencia del conjunto, (iii) restringen la validez de la afirmación a la expresión afectada, (iv) indican el límite inferior del conjunto presupuesto. ${ }^{8}$ A raíz de estas similitudes, puede constatarse la equivalencia o simetría entre estos dos operadores de foco, los cuales han sido sometidos a una serie de análisis basados en textos traducidos.

En primer lugar, se ha analizado la traducción del adverbio de foco alespoň del checo al español y, en segundo lugar, se ha examinado el lexema alespoň como resultado de la traducción del español al checo. En otras palabras, el objetivo fue observar (i) los contextos en los que se «traduce» la información semánticooperacional proporcionada por dicho operador, (ii) los posibles cambios, y (iii) qué contextos y circunstancias implícitas o representadas léxicamente inspiraron a los traductores a utilizar este focalizador en textos traducidos al checo. Para ambos casos, se analizaron 117 unidades de textos de la literatura moderna, obtenidos del corpus paralelo InterCorp. ${ }^{9}$

\footnotetext{
${ }^{8}$ Dejaremos aparte algunas diferencias, las cuales no consideramos relevantes para el análisis actual, p. ej: el adverbio alespoň tiene su variante aspoň, más frecuente en la lengua hablada - diferencia diamediática que no se observa en español; al adverbio alespoň/aspoň corresponden en español dos expresiones: al menos y por lo menos, con significados parcialmente diferentes, pero ambos están integrados en su homólogo checo alespoň/aspoň.

${ }^{9}$ A partir de ahora, todos los ejemplos presentados a lo largo del presente artículo son extraídos del corpus paralelo InterCorp, a no ser que se indique explícitamente otra fuente: RoSEN, A. - VAVŘín,
} 
Las diferencias observadas tornan, por lo tanto, sobre dos aspectos: (i) la conservación del focalizador y (ii) su posición. Por la «conservación» del focalizador en la traducción entendemos cualquier realización lingüística explícita del significado operacional aportado por el focalizador del texto de origen. La «conservación» supone, por ejemplo, el uso de un focalizador equivalente, como se ha observado en (9a-b), de un focalizador sinónimo (9c) o de una construcción (9d). En los ejemplos (10) y (11), por el contrario, la traducción al español no conserva ningún sema de restricción/exclusión, que había sido expresado por el adverbio de foco checo; por lo tanto hemos evaluado estos casos como semas «no conservados»:

(10) a. Ale já jsem nevěděl, zda volá matku svých dětí, nebo svoji mámu, a tak jsem mu aspoň hladil ruku a říkal jsem mu, aby tak nenaříkal.

b. Y yo no sabía si llamaba a la madre de sus hijos o a su propia madre, y $\underline{\boldsymbol{\emptyset}}$ le acaricié la mano, y le dije que no se lamentera de aquella forma.

(11) a. Zvířata zalezla do nejhlubších skrýší a nor a tiskla se jedno k druhému, aby se [alespon̆ trochu] zahřála.

b. Los animales se metían en los más profundos escondites y madrigueras y se apretaban uno contra otro para calentarse [Ø un poco].

Los análisis de la presencia del focalizador alespoñ revelan dos tendencias. Primero, en los textos traducidos del checo al español se observa la tendencia de omitir este elemento, tendencia que corresponde al 18,80\% de las apariciones, como se ha visto en los ejemplos (10) y (11). Por otra parte, en la traducción del español al checo, se observa una preferencia contraria: parece que los traductores optan por insertar un marcador del rema, que, además, contribuye a la semántica y a las implicaturas de lo enunciado, aportando semas de inclusión, exclusión, escalaridad, restricción, etc. Se manifiesta aquí no solo un comportamiento contrario, sino también una tendencia muy marcada, ya que el número de los casos de inserción alcanzan el 30,77 \%, como se ve en los ejemplos (12). Estas tendencias se visualizan en el gráfico 1 al final del capítulo.

$$
\begin{aligned}
& \text { a. }[\ldots] \text { o Ø así parece según el registro. } \\
& \text { a'. }[\ldots] \text { nebo to tak alespoň vypadá. } \\
& \text { b. Yo también tendría que dormir [Ø un rato] } \\
& \text { b'. Já bych si taky měla [alespon̆ na chvíli] zdř́mnout }
\end{aligned}
$$

En lo que se refiere a la posición del adverbio de foco, nos interesó si y hasta qué punto se conserva su posición relativa de focalizador y de elemento en su alcance. Por la «posición conservada», entendemos la situación en el que el focalizador conserva su posición relativa al elemento afectado, sin que importe la posición del conjunto focalizador-elemento actualizado dentro del enunciado. De esta manera, la traducción en (13a') se evaluaría como "posición idéntica», ya que el actualizador tiene en su ámbito operativo la misma expresión/secuencia. Por el

M. - ZASINA, A. J - P. ČERMÁK: Korpus InterCorp-čeština-španělština, verze 10 z 1. 12. 2017. Ústav Českého národního korpusu FF UK, Praha 2017. Accesible desde: http://www.korpus.cz Para la versión española, véase ČERMÁK (2017). 
contrario, la versión en (13b') se ha evaluado como «cambio posicional», ya que el actualizador en la posición final puede tener una interpretación múltiple $\mathrm{y}$, por lo tanto, no idéntica con el texto de origen:

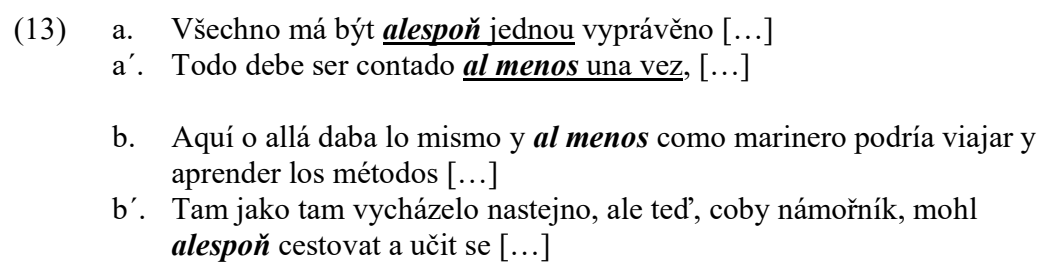

En líneas muy generales, ambas direcciones de la traducción observadas coinciden en la realización de los cambios posicionales, pero difieren en el grado de estos cambios. Así, para la traducción del checo al español hemos identificado el $15,94 \%$ de casos de posiciones cambiadas (el 12,82 \% del número total de la muestra). En los textos traducidos del español al checo, por su parte, los cambios alcanzan un grado algo mayor: el 25,31 \% de los cambios posicionales (el 17,1\% del número total de la muestra); véanse los ejemplos en (14) y (15). Vistas desde la perspectiva contraria, las traducciones analizadas conservan la posición del focalizador en la mayoría de los casos: el $84,04 \%$ en textos traducidos del checo al español (el 67,52\% de la muestra total), y el 74,68\% en textos traducidos del español al checo (el 50,43\% en total).

Además, un análisis más detallado de los tipos del cambio posicional demuestra otras dos tendencias interesantes: por una parte, se evidencia la tendencia del checo en colocar los focalizadores lo más cerca posible del rema propio y, por otra parte, la tendencia del español en aumentar el ámbito operativo del focalizador. Apoya a la primera tendencia el hecho de que todos los cambios posicionales coinciden con una restricción del ámbito operativo: el focalizador en textos traducidos al checo se desplaza para ocupar el lugar vecino al sintagma actualizado (rema propio), abandonando la posición periférica tanto izquierda como derecha, como está ilustrado en los ejemplos en (14). La tendencia del español de aumentar el ámbito operativo del focalizador se refleja en el hecho de que el adverbio de foco se desplaza de una posición contigua al rema propio hacia una más lejana en un $87 \%$ de los cambios posicionales (15).

(14) a. [...] por lo menos mi marido luchó en una guerra [...]

$\mathrm{a}^{\prime}$. [...] můj manžel alespon̆ bojoval ve válce $[\ldots]$

b. Todo debe ser contado una vez al menos, $[\ldots]$

$\mathrm{b}^{\prime}$. Všechno má být alespoň jednou vyprávěno [...]

(15) a. [...] a musili jsme spoléhat, že se jim do rukou [ $\mathrm{v}$ dostane [ Foc alespon̆ [ sN ústřední list, aby se jím řídili.]]]

$\mathrm{a}^{\prime}$. [...] y teníamos que esforzarnos para que [ Foc al menos [ $\mathrm{v}$ recibieran [ sN el órgano central, para seguir sus directivas.]]] 
Las tendencias están resumidas en el siguiente gráfico, en el que el color gris indica los casos en los que la traducción tanto del checo al español, como la del español al checo han conservado de alguna manera el rasgo semántico-operacional del adverbio de foco. Llama especial atención la situación de no reflejar el adverbio del foco (y la información que atribuye a lo enunciado) en las traducciones. Los valores, representados con rayas en el gráfico, deben leerse de dos maneras, dependiendo de la dirección del análisis del lexema alespoň. Por una parte, en textos traducidos del checo al español se observó cómo se refleja la información semántica en los textos meta españoles, por lo cual los casos de la categoría «no reflejados» ha de entenderse como una tendencia de omitir dicha información en el proceso de trasvase. Por otra parte, en los textos traducidos del español al checo se analizó el lexema alespoň como resultado de la decisión del traductor al haberse enfrentado a una señal lingüística explícita que podría haberle llevado a su decisión. Resulta que identificamos casi un $31 \%$ de los casos en los que en el texto de origen no hubo tal señal: en estos casos, la inserción del focalizador fue decisión del traductor, guiado por el contexto (co-texto), sus preferencias y su norma estética. ${ }^{10}$ Una primera conclusión de los hechos observados podría ser la siguiente: dado el nivel relativamente alto de las omisiones/inserciones de los focalizadores, parecen revelarse mecanismos internos de dos sistemas lingüísticos diferentes en cuanto a la señalización de la PFO, que, además, conlleva una implicitación o explicitación de las presuposiciones o implicaturas proporcionadas por los focalizadores. Consecuentemente, se plantea otra pregunta: ¿hasta qué punto son estas tendencias manifestaciones del sistema lingüístico y hasta qué punto son «meras» preferencias de los traductores? Antes de analizar la muestra «traductor por traductor», para poder reflexionar sobre lo ahora expuesto, se presentará otro tipo de focalizador y su traducción del checo al español.

\footnotetext{
${ }^{10}$ ČERMÁK apunta al respecto que «la valoración de la influencia de diferentes factores es complicada, como nos hace ver el mismo LEVÝ: de los tres factores que menciona (el contexto, la memoria del traductor, la norma estética) solo el primero se presta a un análisis directo en el corpus paralelo. Los demás son tal vez analizables de una manera indirecta y todo parece indicar que exigen un estudio translatológico, no puramente lingüístico [...]» (2016:240).
} 


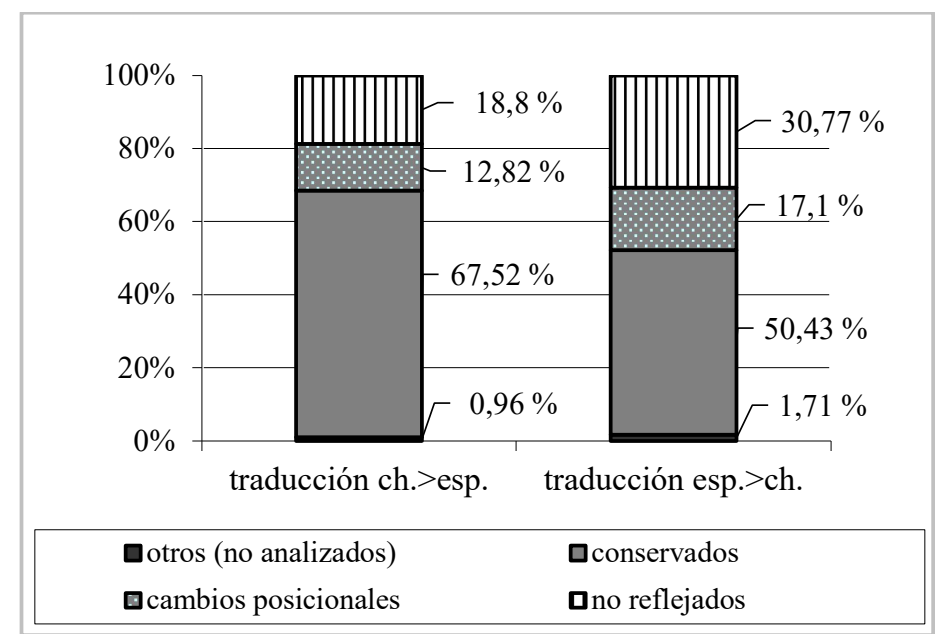

Gráfico 1: El focalizador alespoň en los textos traducidos.

\subsection{El adverbio de foco $i(« y »):$ ¿caso de asimetría?}

En el subcapítulo anterior hemos analizado el adverbio de foco alespon̆, que dispone de un alto grado de equivalencia o simetría funcional con su homólogo español, ya que el significado escalar y exclusivo está presente en los lexemas de ambas lenguas. Por ello, podría ser razonable presuponerse la existencia de cierta simetría en el uso de los focalizadores, al menos en las categorías conceptuales con cierto grado de universalidad -exclusión, inclusión, ejemplaridad, escolaridad, etc. Sin embargo, en los textos traducidos y analizados en ambas direcciones de la traducción, se han observado diferencias en varios aspectos: en la posición del focalizador (tendencia a la posición discontinua en español frente a la continua del checo), y en la presencia del focalizador (más frecuente en checo). En este momento, podría plantearse otra pregunta: ¿Qué ocurre si analizamos tales focalizadores para los que es difícil encontrar su homólogo funcional en la lengua comparada?

Observemos ahora otro elemento checo -focalizador $i$, que procede de la conjunción copulativa pero que ha adquirido el sema de inclusión: de «y» ha pasado a significar «incluso» o "e incluso». ${ }^{11} \mathrm{Si}$ comparamos los focalizadores checos y españoles pertenecientes a la escala aditiva (de inclusión) escalar, observamos que el significado del adverbio de foco $i$ se sitúa entre varios focalizadores españoles, como está ilustrado en el siguiente esquema. La escala de adición representa valores semánticos desde la mera adición (inclusión del elemento en el conjunto), representada por la conjunción y y por el adverbio también, hasta llegar al extremo imaginario del límite, con ciertos rasgos semánticos de sorpresa, énfasis, o de lo inesperado ( $e$ incluso, hasta). En el esquema se evidencia que los valores de $y$, también e incluso se corresponden con sus homólogos checos a, také (taky, rovněz) y dokonce. También los valores de e incluso y hasta parecen concordar con las

${ }^{11}$ Aunque suele mencionarse que el elemento $i$ es conjunción copulativa, hay que subrayar que a diferencia de la conjunción copulativa $a(« \mathrm{y}))$, el focalizador siempre desencadena la presuposición:

(i) Přrišel Honza a Petr. (Ha venido Honza y Petr)

(ii) Přišel Honza i Petr. (Ha venido Honza y \{también/incluso\} Petr) 
expresiones checas a dokonce, až, mientras que el focalizador $y$, por su parte, parece solaparse con varios valores, abarcando el campo semántico desde také («también») hacia el extremo de la escala aditiva.

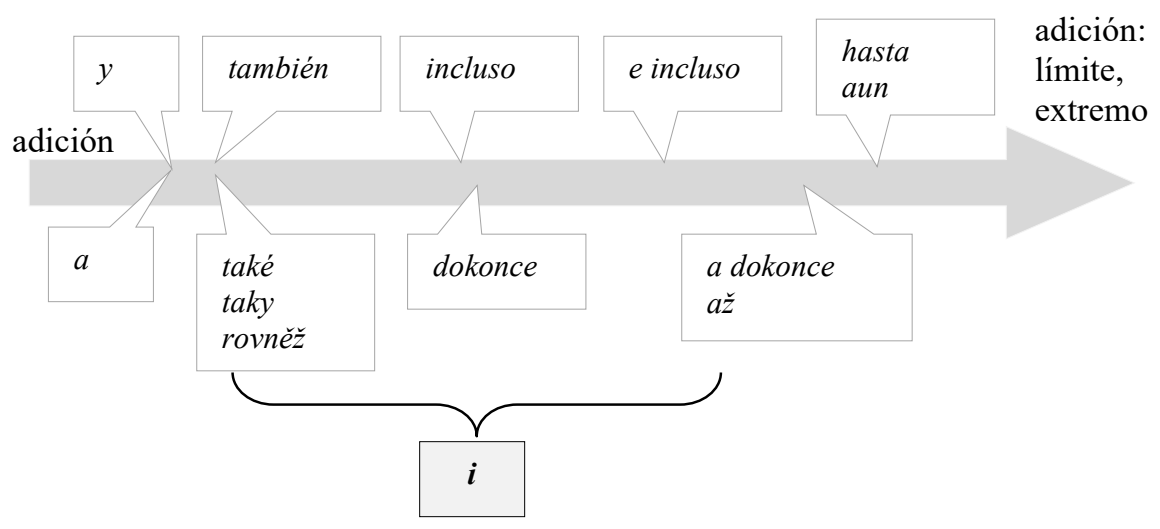

Esquema 1: Comparación de focalizadores de la escala aditiva (checo/español)

Vista la asimetría de los valores, nos hemos planteado la pregunta si esta desproporción se reflejaría en la traducción y, en caso positivo, cuáles serían los contextos que guiaran a los traductores a optar por una u otra solución en el proceso del trasvase. En los ejemplos extraídos del corpus InterCorp (en total 679) ${ }^{12}$ no nos hemos centrado en cambios posicionales, como en el análisis previo, aunque sí los hubo y claramente siguen las pautas indicadas arriba, es decir, tiende a ampliarse el ámbito operativo en las traducciones al español, como se ve en (16).

\section{a. Tuhle jsem rríkal své drahé, že už [ $\boldsymbol{i}$ méně kouříte.]}

$\mathrm{a}^{\prime}$. Incluso le dije a mi esposa que fumaba usted menos

Esta vez, nos ha interesado especialmente la selección de los posibles equivalentes en español, que pueden ser varios, según se ha visto en el esquema. Las soluciones identificadas en el corpus se distribuyen por todo el eje de la aditividad/escalaridad. En la mayoría de los casos, el focalizador $i$ obtuvo en la traducción el valor de grados inferiores de la escala, representados por los valores de también e incluso (los dos juntos representan un $50 \%$ ). El valor extremo de la escala, que interpretaron los traductores y utilizaron consecuentemente adverbios de foco como hasta, aun, se ha observado en un $13 \%$ de los casos. En un $2 \%$ de los casos se aprovecharon otros recursos léxicos para expresar la información semántica del focalizador checo, y en un $36 \%$, el sema de la adición/inclusión escalar ha quedado sin reflejarse. Estas tendencias se resumen en el siguiente gráfico y se ejemplifican abajo.

${ }^{11}$ Esta vez, hemos analizado textos únicamente en la dirección checo>español (screen_lang_ES). Del total 685 hemos descartados 6 ejemplos en los que el focalizador $i$ forma parte de construcciones petrificadas, por ej. en las exclamaciones:

(i) "I ty prevíte! I ty padouchu!" (J. Werich, Fimfárum)

(ii) -iInfame! 


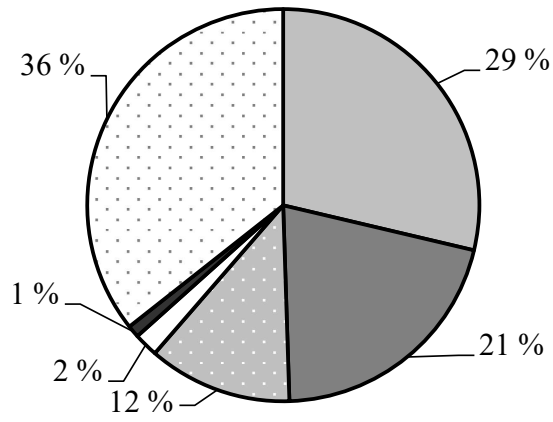

$$
\begin{aligned}
& \text { 口también (29\%) } \\
& \text { 口incluso (21\%) } \\
& \text { 口hasta (12\%) } \\
& \text { 口aun (2\%) } \\
& \text { 口otros (1\%) } \\
& \text { 口 sin reflejar (36\%) }
\end{aligned}
$$

Gráfico 2: El focalizador $i$ en textos traducidos

(17) a. Vysloužila tím jemu $\boldsymbol{i}$ sobě první ránu do tváře.

a'. Ese gesto le valió a ella, y también a su marido, el primer golpe en la cara.

b. Ale $i$ tato malá pravděpodobnost je velkou nadějí.

$\mathrm{b}^{\prime}$. Pero incluso esa probabilidad tan pequeña era una gran esperanza.

c. Onemocněl $\boldsymbol{i}$ Topiltzin, který přebýval se svým otcem a matkou ve vladařském paláci.

c'. Hasta el mismo Topiltzin, que vivía con su padre y su madre en el palacio real, enfermó.

d. "I dnes jsou spolu?" otázal jsem se, ale odpověd' byla jasná $\boldsymbol{i}$ bez ptaní.

d'. ¿ ¿También hoy están juntos? -pregunté, pero la respuesta estaba clara aun sin preguntar.

Si aceptamos que en la escala aditiva hay dos grupos semánticos claramente diferenciados, uno con el sema de adición/inclusión (también, incluso) y otro con el sema del límite (e incluso, hasta, aun), y si comparamos las traducciones del focalizador $i$, podemos observar que el primer valor se ha interpretado en la mayoría de los casos (un $78 \%$ de los casos en los que se ha reflejado la semántica del focalizador), mientras que el valor del «extremo» se ha adjudicado tan solo a un $22 \%$ de los casos. Un análisis más detenido de los contextos más amplios de lo que ofrecen las concordancias del corpus, es decir a nivel del párrafo, revelan que fue el contexto inmediato el que proporcionó las pistas para interpretar el focalizador $i$ de una $u$ otra manera. Las oraciones en (18) son ejemplos del valor extremo - este puede comprobarse con la (im)posibilidad de conmutación por otros elementos de la misma escala, comprobada por las dudas del hablante que puedan surgir ante tal cambio: ${ }^{13}$

${ }^{13}$ Por razones del espacio no entramos aquí en la discusión sobre aspectos del contexto, aunque claro está que el la interpretación de lo enunciado se realiza de manera composicional; en el mecanismo entran varios factores como conocimientos generales, conocimientos del contexto, significado y sentido. También es el co-texto el que determina sustancialmente la interpretación: así, la 
(18) a. Co je to Sodoma? Pravíte, že je to město nepravosti. Ale když Sodomští bojují, nebojují za své nepravosti, nýbrž za něco lepšího, co bylo nebo bude; a $\boldsymbol{i} /$ /??také ten nejhorší může padnout za všechny. Sodoma, to jsme my všichni; a mám-li nějakou cenu před Hospodinem, at' ji přičte Sodomě, a nikoli mně. Co ještě mluvím?

b. ¿Qué es Sodoma? Decís que es una ciudad viciosa. Pero cuando los sodomitas luchan, no lo hacen por sus vicios, sino por algo que fue o que será mejor. Hasta /??también el peor puede sacrificarse o caer por los demás. Sodoma somos todos nosotros. Y si tengo algún mérito a los ojos de Dios, que se lo aplique a Sodoma y no a mí. ¿Qué digo todavía?

\section{Análisis de las traducciones por diferentes traductores}

A raíz de todo lo expuesto hasta ahora, podríamos formular las conclusiones sobre las tendencias deducidas de la muestra. Primero, podría parecer que el checo tiende a utilizar recursos léxicos en mayor medida que el español, ya que los datos demuestran que durante la traducción al checo se «añaden» estos elementos, mientras que en la traducción al español se «omiten» (tendencia observada tanto con el focalizador alespoň como con $i$ ). También parecería legítimo considerar un análisis de textos traducidos como una herramienta eficaz e idónea para revelar el funcionamiento interno de una lengua. Además, la cuantificación de los respectivos análisis parciales alcanza niveles parecidos y suficientemente altos para poder ser comprendidos e interpretados como una tendencia bien pronunciada.

Sin embargo, deberíamos plantearnos en este momento toda una serie de preguntas sobre los posibles factores desfavorables e inconvenientes que pudieran haber obstaculizado nuestro análisis, o, en general, pudieran obstaculizar la interpretación unívoca de este tipo de análisis. Recordemos que se ha trabajado con textos traducidos, proporcionados por un corpus paralelo. ¿Hasta qué punto pueden intervenir e influir en los resultados los factores como la explicitación y generalización de la traducción? ¿Hasta qué punto son decisivos el idiolecto y las competencias del traductor?

Por todo ello, hemos decidido sumergirnos en otro análisis: nos hemos centrado en el actualizador aspon̆ (variante de alespon̆), cuyas traducciones solamente se observaron en textos traducidos del checo al español, simplemente por el hecho de que, desgraciadamente, todas las traducciones del español al checo contenidas en el corpus paralelo InterCorp fueron elaboradas tan solo por autores checos; lo cual no habría permitido, obviamente, comparar grupos de traductores divididos según su lengua materna. El propósito de este último análisis es examinar lo siguiente: si los resultados que acabamos de ver parecen revelar un menor uso de las partículas en español, y la inserción de las partículas en cuestión en textos traducidos al checo,

i. ¿puede deducirse de ello que las diferencias observadas reflejan diferencias sistémicas de las lenguas?

ii. $\quad 0$ ¿estamos ante las tendencias de explicitación o normalización (según

interpretación de valores escalares altos se ve apoyada por la aparición de algunos adjetivos calificativos, de superlativos, etc. 


\section{LEVÝ 1971)?}

iii. $\quad \mathrm{y}$, por último, ¿es posible que pueda haber una relación entre las tendencias de simplificación, explicitación, normalización y nivelación y la lengua materna del traductor?

Hemos analizado los textos traductor por traductor que se agrupan de esta manera: (a) textos hechos por traductores checos, (b) tándem checo-español y (c) traductores españoles. Hay que advertir, sin embargo, que el número de la muestra no es muy alta, ya que comprende solo 404 ítems en total. Aun así, creemos que los resultados pueden ser de interés.

Suponíamos que si el español es una lengua con un menor grado del uso de los focalizadores, era de esperar que la «conservación» del lexema aspoň (traducido de diferentes manera, manteniendo el sema de «un grado mínimo», como en por lo menos, al menos, como mínimo, etc.), se observaría sobre todo en los traductores cuya lengua materna era el checo. No obstante, los resultados, sorprendentemente, indican todo lo contrario: el mayor número de los lexemas «conservados» se observa en los textos traducidos por el tándem español-checo (el 81,81\%), seguido por los traductores españoles (el 78,27 \%); los traductores checos son los que reflejaron la partícula aspon̆ a nivel léxico en menor grado (el $60 \%$ ). Todos los resultados y aspectos observados se visualizan en la siguiente tabla.

\begin{tabular}{|c|c|c|c|c|c|c|}
\hline Total: 404 ítems & \multicolumn{2}{|c|}{$\begin{array}{l}\text { traductores checos } \\
\text { (5 libros, } 36 \text { casos) }\end{array}$} & \multicolumn{2}{|c|}{$\begin{array}{l}\text { tándem checo-español } \\
\text { (4 libros, } 55 \text { casos) }\end{array}$} & \multicolumn{2}{|c|}{$\begin{array}{l}\text { traductores españoles } \\
\text { (15 libros, } 313 \text { casos) }\end{array}$} \\
\hline $\begin{array}{l}\text { lexemas no } \\
\text { conservados }\end{array}$ & \multicolumn{2}{|l|}{$12(30 \%)$} & \multicolumn{2}{|c|}{$10(18,18 \%)$} & \multicolumn{2}{|c|}{$68(21,72 \%)$} \\
\hline lex. conservados: & \multicolumn{2}{|l|}{$24(60 \%)$} & \multicolumn{2}{|c|}{$45(81,81 \%)$} & \multicolumn{2}{|c|}{$245(78,27 \%)$} \\
\hline $\begin{array}{l}\text { con posición } \\
\text { idéntica }\end{array}$ & $\begin{array}{l}19 \\
(79,2 \\
\%)^{14}\end{array}$ & $(52,78 \%)^{15}$ & $\begin{array}{l}38 \\
(84,44 \%)\end{array}$ & $(69,09 \%)$ & $\begin{array}{l}210 \\
(85,71 \%)\end{array}$ & $(88,82)$ \\
\hline $\begin{array}{l}\text { con cambios } \\
\text { posicionales }\end{array}$ & $\begin{array}{l}5 \\
(20,83 \%)\end{array}$ & $(13,88 \%)$ & $\begin{array}{l}7 \\
(15,55 \%)\end{array}$ & $(30,91 \%)$ & $\begin{array}{l}35 \\
(14,28 \%)\end{array}$ & $(11,18 \%)$ \\
\hline $\begin{array}{l}\text { ante- } \\
\text { posición }\end{array}$ & $\begin{array}{l}4 \\
(80 \%)\end{array}$ & $(11,11 \%)$ & $\begin{array}{l}4 \\
(57,14 \%)\end{array}$ & $(7,27 \%)$ & $\begin{array}{l}21 \\
(60 \%)\end{array}$ & $(6,07 \%)$ \\
\hline $\begin{array}{l}\text { pos- } \\
\text { posición }\end{array}$ & $\begin{array}{l}1 \\
(20 \%)\end{array}$ & $(2,77 \%)$ & $\begin{array}{l}3 \\
(42,85 \%)\end{array}$ & $(5,45 \%)$ & $\begin{array}{l}14 \\
(40 \%)\end{array}$ & $(4,47 \%)$ \\
\hline
\end{tabular}

Tabla 1: Aspoň en textos traducidos del checo

Los resultados - repetimos que bastante restringidos - confirman la tendencia de los cambios posicionales observados ya antes: en casos en los que se «conserva» el focalizador, suele cambiarse su posición desde el rema propio hacia el principio del sintagma en el que actúa. También puede constatarse la tendencia de omitir estos elementos en textos meta, aun mayor que en el caso del lexema alespoň: el 23,3\% frente al 18,80\%. De este modo, parecerían reafirmarse dichas tendencias, lo cual

\footnotetext{
${ }^{14}$ Las cifras en las primeras columnas expresan números absolutos de apariciones y sus números relativos $(\%)$ dentro de la categoría superior.

${ }^{15}$ Las cifras en las segundas columnas expresan números relativos (\%) respecto al número total.
} 
podría llevarnos a conclusiones sobre las diferencias a nivel del sistema lingüístico. Sin embargo, no hay que perder de vista que estamos trabajando con cantidades poco representativas, y que, también, hay una considerable diferencia entre las soluciones de los traductores. Se ha observado, por lo tanto, que mientras que algunos traductores sistemáticamente conservan los focalizadores (es decir, la información semántica/pragmática), sea con actualizadores equivalente o con otras construcciones, otros los omiten. Así, algunos traductores, en un mismo libro «tradujeron» la partícula aspoň en $99 \%$ de los casos (o incluso el $100 \%$ en el caso de un traductor), otros tendían más a omitir los actualizadores (el caso más extremo era el $53,65 \%$ de las omisiones).

\section{Conclusión}

En el texto anterior, hemos intentado ver las diferencias de los adverbios de foco a través del corpus paralelo, es decir, a través de textos traducidos, aun a sabiendas de que la lengua traducida puede sufrir ciertos cambios y diferir de la producción «espontánea». Como apunta ČERMÁK (2016 : 234) «las dudas al respecto de la naturaleza de la lengua traducida se han convertido en el argumento más importante en contra de la metodología de los corpus paralelos». Igualmente, en nuestro análisis se revelan ciertos cambios, especialmente los relacionados con la posición de los focalizadores y a la ocurrencia de los mismos. Sin embargo, hasta que no se compare la naturaleza de la lengua meta con la original, será difícil llegar a conclusiones significativas y relevantes. Por eso, ofrecemos la comparación de las apariciones de los focalizadores en textos de origen y en textos meta, visualizada en el siguiente gráfico. El color gris representa la frecuencia (frecuencia reducida media, average reduced frequency, ARF) de los focalizadores aspon̆, alespon̆, por lo menos, al menos en textos originales; el color blanco representa textos traducidos.

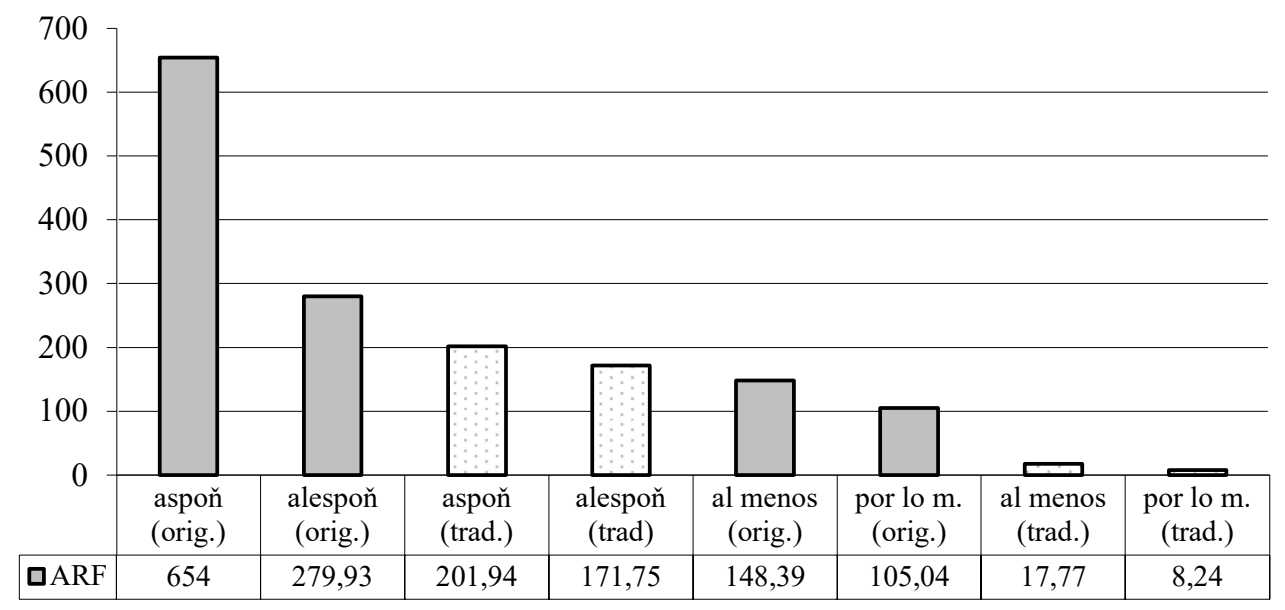

Gráfico 3: ARF de los focalizadores en textos originales y traducidos. 
Las tendencias son más que obvias. Primero, la aparición de los focalizadores es mayor en los textos checos, tanto originales como tema, tendencia que comprueba el uso de los focalizadores mucho más frecuente en la lengua checa que en la lengua española. Segundo, la ARF de los focalizadores en textos traducidos al checo del español más alta que la de los textos originales subraya la conclusión observada en los análisis previos: la tendencia de insertar los marcadores de foco aún donde no hubo señal lingüística explícita en el texto de origen. Tercero, los textos traducidos tanto del checo como del español muestran tendencias idénticas: sus frecuencias más bajas que los respectivos textos de origen parecen comprobar la inclinación hacia la implicitación de la información en los textos traducidos, especialmente en este caso de recursos de semántica operacional - los marcadores de foco. Sin embargo, debido al número restringido de casos, no se ha comprobado la relación entre dicha tendencia y la lengua materna del traductor.

\section{Agradecimientos}

La investigación que subyace a este proyecto ha sido financiada mediante la beca de investigación GAČR P406/17-20553S. Una parte de la contribución fue presentada en el congreso Ad translationem: Homenaje a Jiř́ Levý, celebrado en Brno, 26 -27 de octubre de 2017. También deseamos expresar nuestros agradecimientos a los evaluadores anónimos por sus excelentes comentarios, que permitieron mejorar el texto.

\section{BIBLIOGRAFÍA}

ADAM Martin (2011), Towards a Syntactic Semantic Typology of Presentation Scale Sentences in Fiction Narratives, Brno Studies in English, 37, 1, p. 5-19.

ADAM Martin (2014), Prezentační versus kvalifikační škála: interpretace hraničních př́padů v FSP analýze narativního textu, Časopis pro moderni filologii, 96, 2, p. $180-196$.

Atienza Peñarrocha Antonio (2007), El Genio de Bazán. La Aventura de la historia, 105, p. 50-57.

AUROVÁ Miroslava (2016a), La perspectiva funcional de la oración (PFO) en la traducción: Paradigmas e instrucciones selectivas, Mutatis Mutandis, 9, 2, p. 383-400.

AUROVÁ Miroslava (2016b), El orden de palabras y el dinamismo comunicativo: una contribución al estudio contrastivo del español y checo, Hermenéus, Revista de Traducción e Interpretación, 18, p. 27-58..

Aurová Miroslava (2017), Srovnání aktuálního členění v češtině a španělštině: textovělingvistický př́stup, České Budějovice, Jihočeská univerzita, Episteme.

ČERMÁK Petr (2016), La traducción como proceso de decisiones: su reflejo en los corpus paralelos, Mutatis Mutandis, 9, 2, p. 224-246.

ČERMÁK Petr (2017), Korpus InterCorp - španělština, verze 11 z 15. 12. 2017. Ústav Českého národního korpusu FF UK, Praha. [http://www.korpus.cz]

DANEŠ František, GREP, Miroslava, HLAVSA Zdeněk (1987), Mluvnice češtiny 3. Skladba, Praha, Academia.

FERRARi Laura, GiAMMATTEO Mabel, ALBANO Hilda (2011), Operadores de foco: el caso de incluso, hasta, solo y aun. Cuadernos de la ALFAL, 3, p. 30-41. 
FIRBAS Jan (1974), Some aspects of the Czechoslovak approach to problems of functional sentence perspective, in: DANEŠ František (éd.) Papers on Functional Sentence Perspective, Praha, Academia, p. 11-37.

FIRBAS Jan (1989), Degrees of communicative dynamism and degrees of prosodic prominence, Brno Studies in English, 18, p. 21-66.

HAJIČOVÁ Eva (1995), Postavení rematizátorů v aktuálním členění věty. SaS 56, p. 241-251.

KOVACCI Ofelia (2000), El adverbio, in : BOSQUE Ignacio, DEMONTE Violeta (éd.), Gramática descriptiva de la lengua española, Madrid, Espasa Calpe, p. 705780.

KrÁlová Jana, Cuenca Drouhard Miguel J. (éd.) (2013), Jiři Levý: una concepción (re)descubierta [Monográficos de la revista Herméneus], Soria, Vertere.

FernándeZ LaguniLla Marina, De Miguel Elena (1999), Relaciones entre el léxico y la sintaxis: adverbios de foco y delimitadores aspectuales, Verba: Anuario galego de filoloxía, 26, p. 97-128.

LEVÝ Jiří (1967), Translation as a decision process, in To Honor Roman Jakobson: Essays on the occasion of his seventieth birthday, vol. 2, The Hague, Mouton, p. 1171-1182.

LEVÝ Jiří (1971), Bude literární věda exaktni vědou?, Praha, Československý spisovatel.

RAE-ASALE (2009), Nueva gramática de la lengua española. Morfología y sintaxis, Madrid, Espasa Calpe.

Rosen,A., VAVŘín M, ZASINA A. J., ČERMÁK P. (2017), Korpus InterCorp čeština-španělština, verze $10 \mathrm{z}$ 1. 12. 2017, Praha, Ústav Českého národního korpusu FF UK. [http://www.korpus.cz]

SÁNCHEZ LÓPEZ Cristina (1999), Los cuantificadores: clases de cuantificadores y estructuras cuantificativas, in : BOSQUE Ignacio, DEMONTE Violeta (éd.), Gramática descriptiva de la lengua española, Madrid, Espasa Calpe, p. 705780.

SgALl Petr, HAJIČOVÁ Eva (1997), Remarks on Focus Sensitive Particles : in KAMP H. y PARTEe B. H. (éd.), Context-Dependence in the Analysis of Linguistic Meaning 2, Amsterdam, Elsevier, p. 87-92.

ŠTĚPÁNKOVÁ Barbora (2014), Aktualizátory ve výstavbě texto, zejména z pohledu aktuálního členění, Praha, UFAL.

UHLířová Ludmila (1987), Knižka o slovosledu, Praha, Academia. 